Proceedings

\title{
Intelligent Machine Parts: Challenges in the Condition Monitoring of Elastomer Gaskets with Integrated Sensors ${ }^{\dagger}$
}

\author{
Daniel Gräbner 1,*, Robert Zahn ${ }^{2}$, Ulrich Giese ${ }^{2}$ and Walter Lang ${ }^{1}$ \\ 1 Friedrich-Wilhelm-Bessel-Institute Research Society, 28359 Bremen, Germany; info@fwbi-bremen.de \\ 2 Deutsches Institut für Kautschuktechnologie e.V., 33, 30519 Hannover, Germany; \\ robert.zahn@dikautschuk.de (R.Z.); info@dikautschuk.de (U.G.) \\ * Correspondence: graebner@fwbi-bremen.de; Tel.: +49-421-2186-2575 \\ + Presented at the Eurosensors 2017 Conference, Paris, France, 3-6 September 2017.
}

Published: 18 August 2017

\begin{abstract}
Smart factories are supposed to provide an overview on the current status of installed production machines. In order to collect data, intelligent machine parts have to be designed. We present a method to monitor the condition of elastomer gaskets, which are crucial parts of many machines. The monitoring is done by a strain gauge, which is integrated into the gasket. This paper describes the overall concept of the monitoring system as well as the challenges by varying temperature and pressure of the sealed fluid on the sensors signal.
\end{abstract}

Keywords: elastomer gasket; condition monitoring; material integrated sensing; intelligent machine parts

\section{Introduction}

Gaskets are small, yet crucial parts of many technical systems. Failure of a gasket can lead to malfunction or failure of the system. It is of particular interest to monitor the condition of elastomer gaskets in order to predict and prevent failure. A study about the energy loss in compressed air systems within the European Union shows an annual loss of energy of approx. 12.8 billion kWh caused by leakage only [1]. Therefore, prevention of leakage can lower the amount of energy needed. Condition monitoring of gaskets might as well lower maintenance costs by introducing flexible, degradationbased maintenance cycles, thereby, decreasing down times of machines and production systems.

\section{Degradation Mechanism of Elastomer Gaskets}

Elastomers show a complex aging behavior. Two competing processes mainly determine the degradation: polymer chain splitting and repolymerization. Depending on which process dominates during aging, elastomers either soften or harden over time [2]. Transferring this behavior to an elastomer gasket, the gasket tends to plastically flow or plasticize and get brittle, respectively, over its lifetime. A commonly used indicator for the degradation status of a gasket is the compression set CS, which is defined as [3].

$$
\operatorname{CS}[\%]=\frac{h_{0}-h_{2}}{h_{0}-h_{1}} \times 100
$$

with $h_{0}$ being the initial height of the gasket, $h_{1}$ being the height of the gasket while compressed and $h_{2}$ being the height of the gasket after the compression is released. Both aging mechanisms cause a loss of elastic restoring forces within the material, thereby, determining the compression set. The measurement of the compression set is only possible after the gasket has been uninstalled. Hence, it is desirable to establish a method to monitor the compression set during the lifetime of a gasket. 


\section{Monitoring of Elastomer Gaskets with Integrated Strain Gauges}

The decrease in the elastic restoring force of the gaskets material can be measured by a strain gauge, which is integrated into the gasket. When the gasket is installed and compressed, forces are transferred from the gasket to the sensor. This leads to an elongation of the strain gauge and, hence, a measurable change the strain gauges signal. The general concept is depicted in Figure 1.

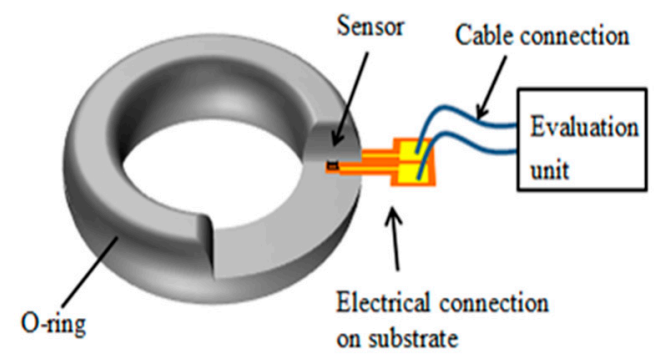

Figure 1. Concept of sensor integration into O-ring gasket.

The integration of the sensor into the gasket is done during the fabrication of the gasket by compression molding. The elastomer material is pressed into the final shape and vulcanized to $25 \%$ of the final crosslinking. A small hole is cut into this preform and the sensor is put inside. The actual strain sensing structure of the strain gauge is placed at the center of the gaskets cross sectional diameter. Then the vulcanization process is continued. Computer tomographic analysis shows, that the sensor stays in place during the final vulcanization step.

For expedited aging experiments an HNBR elastomer has been chosen as gasket material and a simple, Polyimide-foil based resistive strain gauge has been fabricated. The sensor was integrated into a gasket as described above. Figure 2 shows the strain gauges resistance during expedited aging from previously published experiments [4]. In these experiments, the temperature during aging was stable and no pressure was applied to the gasket from within the sealed volume. After aging and decompression a remaining zero-shift of the strain gauges resistance of $7.5 \Omega$ was recorded. A compression set of $34 \%$ was measured, indicating an advanced degradation of the gasket.

\begin{tabular}{|c|c|c|c|c|c|c|}
\hline \multirow{3}{*}{ 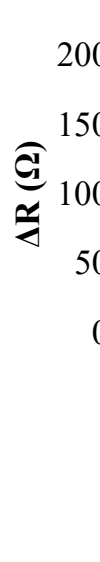 } & $23^{\circ} \mathrm{C}$ & $70^{\circ} \mathrm{C}$ & $70^{\circ} \mathrm{C}$ & $23^{\circ} \mathrm{C}$ & & \\
\hline & (a) & (b) & (c) & (d) & (e) & (f) \\
\hline & 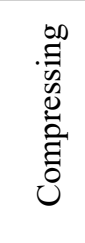 & 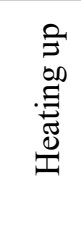 & $\begin{array}{l}\text { Holding temperatur/ } \\
\text { artificial aging }\end{array}$ & $\begin{array}{l}\stackrel{00}{\Xi} \\
: 0 \\
0 \\
0\end{array}$ & $\begin{array}{l}\stackrel{0}{0} \\
0 \\
0 \\
0 \\
0 \\
0 \\
0 \\
0 \\
0\end{array}$ & \\
\hline
\end{tabular}

Figure 2. Change of resistance in a long-time measurement of a strain gauge embedded in a compressed O-ring: (a) Resistance during compression; (b) Raise of temperature to $70{ }^{\circ} \mathrm{C}$; (c) Resistance change at $70{ }^{\circ} \mathrm{C}$ within $72 \mathrm{~h}$; (d) Cooling; (e) Releasing compression; (f) Remaining zero-shift [4].

\section{Challenges in Condition Monitoring by Varying Environmental Conditions}

Under controlled and stable environmental conditions, the monitoring of a gaskets degradation is possible. However, in most applications environmental conditions will vary. Temperature has a 
major influence on the strain gauges resistance, as can be seen in Figure 2. The change in resistance caused by increasing temperature is much greater than the change by the compression of the gasket and, especially, the change in resistance caused by aging. Therefore, varying temperature during the gaskets lifetime can lead to a wrong estimation of the current state of degradation of the gasket.

A simple way to compensate the influence of temperature on the strain gauges signal is to add a second, passive structure to the strain gauge as shown in Figure 3(left). The left meandering structure is used as active strain gauge and the orthogonally placed right meandering structure is a passive strain gauge. Both strain gauges are connected in a half-bridge layout. Figure 3(right) shows the temperature dependency of the strain gauges signal in a compressed gasket. The active as well as the passive strain gauges show strong temperature dependency when used individually, whereas the half-bridge almost completely compensates the influence of temperature.
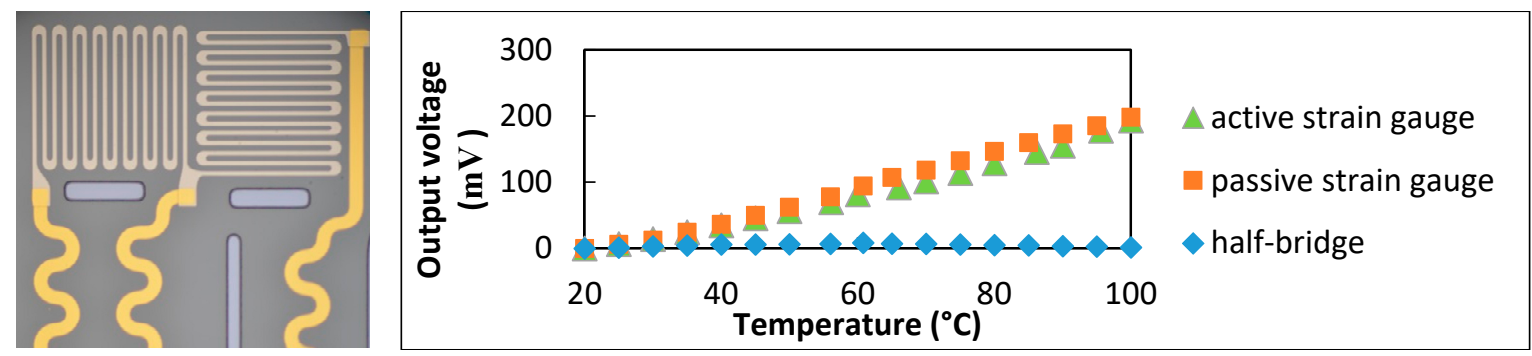

Figure 3. Temperature compensation by half-bridge strain gauge design: Measurement results (right); strain gauge design (right).

FEM simulation indicates, that not only the temperature has an influence on the strain gauges signal and, therefore, on the capability to monitor a gaskets condition, but also lateral pressure on the gasket from inside of the sealed volume might cause an unneglectable change in the measurement signal. The measurement setup to determine the influence of this pressure is depicted in Figure. The gasket is placed between to aluminum plates; one of which has an inlet for compressed air (a). The gasket is then compressed by applying a force on the top plate (b). In step (c), compressed air creates pressure inside the sealed space between the plates.
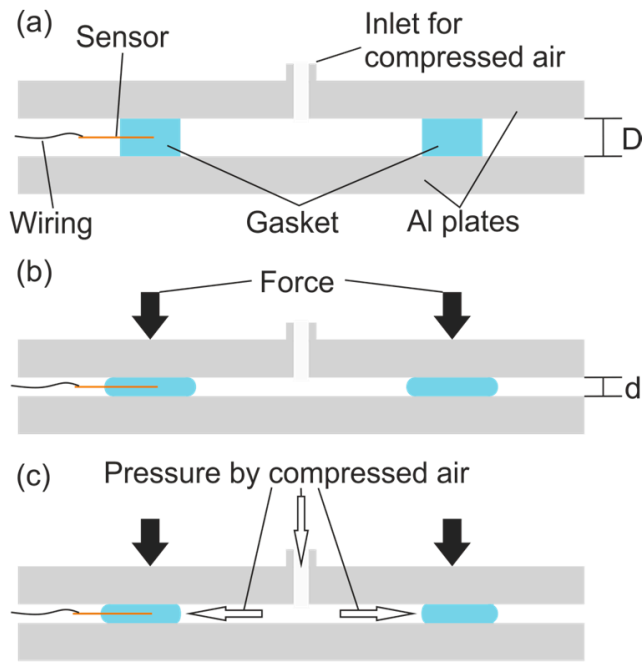

Figure 4. Measurement setup: (a) Gasket is placed between to plates; (b) Gasket is compressed; (c) Pressure is applied to the sealed space.

The pressure is varied from 0 to 7 bar. The initial compression of the gasket increases the resistance from $1269 \Omega$ to $1327 \Omega$, which indicates a large elongation of the strain gauge. Figure shows the change of the strain gauges resistance over time with different applied pressures. When a pressure of 7 bar is applied to the sealed volume, the resistance decreases by approx. $8 \Omega$. The average rate of the change of resistance is around $1 \Omega /$ bar. As the change in resistance caused by the applied pressure 
is in the same range as the change caused by aging, the systems reliability for condition monitoring is limited.

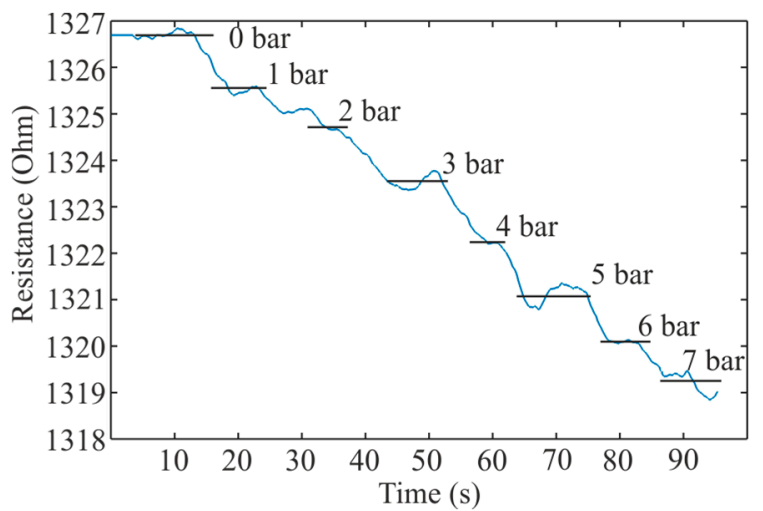

Figure 5. Measurement results: Change of resistance versus time, stages of applied pressure are marked.

\section{Conclusions}

The monitoring of the condition of an elastomer gasket during its lifetime with an integrated strain gauge is possible under controlled environmental conditions. The influence of varying temperature on the strain gauges signal can be compensated by adding a second, passive resistive structure to the strain gauge. By contrast, the influence of lateral pressure applied to the gasket causes an unneglectable change in the strain gauges signal, thereby, compromising the system's ability to monitor the gaskets condition reliably. Hence, in future work we will focus on integrating a pressure sensor into the gasket, which can measure the remaining elastic restoring force within the gasket vertically and at the same time is insensitive to lateral deformation.

Acknowledgments: This research was conducted as part of the IGF-project Nr. 18695N from the German Research Association for Measurement, Controls and Systems Engineering supported by the AiF in the funding structure for industrial co-operative research (IGF) by the Federal Ministry of Economics and Technology based on a decision from the German Bundestag.

Conflicts of Interest: The authors declare no conflict of interest. The founding sponsors had no role in the design of the study; in the collection, analyses, or interpretation of data; in the writing of the manuscript, and in the decision to publish the results.

\section{References}

1. Radgen, P.; Blaustein, E. Compressed Air Systems in the European Union Energy, Emissions, Savings Potential and Policy Actions; LOG_X Verlag GmbH: Stuttgart, Germany, 2001.

2. Torrejon, Y.N.; Giese, U.; Santoso, M. Consumption and reaction mechanism of antioxidants during thermal oxidative aging. Kautschuk Gummi Kunststoffe 2012, 65, 25-31.

3. Abts, G. Prüfung von Kautschuken und Elastomeren. In Einführung in die Kautschuktechnologie; Hanser: München, Germany, 2007.

4. Schotzko, T.; Reuter, M.; Lang, W. Sensor integration in rubber gaskets for structural health monitoring made by compression molding. Polym. Test. 2015, 48, 31-36.

(C) 2017 by the authors. Licensee MDPI, Basel, Switzerland. This article is an open access article distributed under the terms and conditions of the Creative Commons Attribution (CC BY) license (http://creativecommons.org/licenses/by/4.0/). 